\title{
Artefatos culturais e a abordagem sobre gênero e sexualidade: a revista Nova Escola
}

\author{
Rita de Cássia Petrenas ${ }^{1}$
}

\begin{abstract}
RESUMO
O trabalho teve como objetivo analisar os artigos sobre a temática sexualidade e gênero presentes na revista Nova Escola, no período de 2000 a 2017. Trata-se de uma pesquisa documental, utilizando para análise dos artigos a Análise de Conteúdo Temática. A pesquisa identificou um considerável número de artigos que abordam assuntos variados que podem enriquecer o aprendizado e a prática docente, bem como as experiências construídas no cotidiano das escolas. Conclui-se que para tanto, é preciso que os educadores percebam os limites da produção jornalística destinada aos docentes. Dentre esses limites podemos apontar a linguagem simplificada, textos com caráter prescritivo, valorização de modismos e inovações pedagógicos, e a aposta exagerada no empenho dos docentes para achar a solução para os problemas pedagógicos, culturais e sociais que abrangem a prática educativa.
\end{abstract}

PALAVRAS-CHAVE: Sexualidade. Gênero. Artefatos culturais.

Cultural artifacts in the approach of gender and sexuality: the Nova Escola magazine

\begin{abstract}
The work analyzes the articles on the theme sexuality and gender present in the magazine Nova Escola, from 2000 to 2017. It is a documentary research, using for analysis of the articles thematic content analysis. The research identified a considerable number of articles that address varied subjects that can enrich the learning and the teaching practice, as well as
\end{abstract}

\footnotetext{
1 Doutora em Educação. Integrante do NUSEX - UNESP Araraquara, ASSER/UNICEP, São Paulo, Brasil. https://orcid.org/0000-0001-8116-2607.ritapetrenas@gmail.com.
} 
the experiences built in the daily life of the schools. In conclusion, it is necessary for educators to understand the limits of journalistic production for teachers. Among these limits we can point out the simplified language, prescriptive texts, appreciation of fads and pedagogical innovations, and the exaggerated bet on the teachers' commitment to find the solution to the pedagogical, cultural and social problems that encompass the educational practice.

KEYWORDS: Sexuality. Genre. Cultural artifacts.

Se alguma coisa nos anima a escrever é a possibilidade de que esse ato de escritura, essa experiência em palavras, nos permita liberar-nos de certas verdades, de modo a deixarmos de ser o que somos para ser outra coisa, diferentes do que vimos sendo. Jorge Larrosa Bondía e Walter Kohan $(2002$, p. 1)

\section{Introdução}

É inevitável que o tema da sexualidade adentre na instituição escolar, esperando-se que, nos dias de hoje, a formação docente em relação à temática torne-se além das questões de doutrinação, "receituário" e atitudes preconceituosas, pois no contexto escolar é preciso ética, não moralismo, tendo como base o princípio de formação do indivíduo enquanto ser histórico na busca de sua emancipação.

Apesar de todo o contexto social, cultural e político que permeia a educação sexual nas escolas, esse tema ainda conta com amarras para serem implantadas de modo adequado, uma vez que não basta somente a publicação de documentos oficiais e literatura científica significativa para garantir ao docente as condições necessárias e adequadas para seu trabalho.

Compreendendo que a escola, além de ser um espaço de contradições, de poderes divergentes e de antagonismos, é também espaço privilegiado para a luta contra os preconceitos e discriminações e o/a docente assume parte significativa dessa tarefa. 
A temática da educação/orientação sexual e a necessidade de abordá-la enquanto parte da formação docente tem sido estudados por diversos pesquisadores, dentre eles; (LOURO, 1997, 2010; NUNES e SILVA, 2000; PETRENAS, 2015; RIBEIRO, 1990, 2002, 2004). Embora existam pesquisas consolidadas sobre o tema e também grupos das diversas instituições de ensino superior que se debruçam sobre perspectivas e estudos, pode-se dizer que ainda existem lacunas no âmbito escolar, carecendo de investigações que abordem esses temas integrados, ou seja, sexualidade no contexto escolar e formação docente.

Devemos considerar que a formação docente vem apresentando vários caminhos de ordem epistemológica, social, prática, relacionados à diversidade das disciplinas do currículo e dos artefatos culturais.

Compreendemos os artefatos culturais como resultados de processos de produções culturais que contém pedagogias culturais que ensinam modos de ser e estar no mundo, construindo e reproduzindo significados sociais (STEINBERG,1997). As pedagogias culturais podem ser concebidas enquanto processos sociais que ensinam, compreendendo que o processo educacional ocorre também além da instituição escolar.

Depreendemos que as pedagogias culturais são processos capazes de construir e reconstruir nossas identidades e subjetividades no sentido educacional, cultural, social, pois "o cultural torna-se pedagógico e a pedagogia torna-se cultural" (SILVA, 2009, p. 139). Incluímos as pedagogias culturais situadas no campo dos Estudos Culturais, que se originou na Inglaterra, a partir da segunda metade do século XX, abrangendo os produtos culturais como influenciadores da reprodução social.

O termo "pedagogia cultural" é apresentado por Steinberg e Kincheloe (2001) para justificar a educação que ocorre além dos muros escolares, pois entendem que a educação pode ocorrer "numa variedade de áreas sociais, incluindo, mas não se limitando à escolar. Áreas pedagógicas são aqueles lugares onde o poder é organizado e difundido, incluindo-se bibliotecas, TV, 
cinemas, jornais, revistas, brinquedos, propagandas, videogames, livros, esportes, etc." (STEINBERG; KINCHELOE, 2001, p. 14).

Entretanto, a escola pode ter papel de destaque ao abordar de maneira sistemática as concepções de sexualidade, sexo e gênero. Dessa forma, os artefatos culturais relacionados a temática colaboram também com a formação docente, e nesse viés de análise, em específico, selecionamos a revista Nova Escola como objeto de estudo.

Num mundo em que as informações são constantes e assumem um caráter transitório, pois não se consolidam em conhecimentos válidos e significativos, os artefatos culturais assumem papel relevante na regulação e subjetivação de tomada de decisões e posturas.

Desse modo, tendo como proposta de pesquisa a temática da sexualidade e gênero atrelada à formação docente, propomos analisar a Revista Nova Escola, no período dos anos 2000 a 2017, como um importante artefato cultural que colabora significativamente para a formação docente de maneira formal e informal, pois é veiculada nas diversas instituições de ensino e nos últimos anos também online, utilizada nas leituras de trabalho coletivo (HTPC/ATPC) ${ }^{2}$ e nos cursos de licenciatura como complemento das aulas ou mesmo leitura dos/as estudante.

Segundo dados do Instituto Verificador de Circulação (IVC), em 2015, a Revista Nova Escola impressa ocupou o $147^{\circ}$ lugar em termos de circulação e a Revista Nova Escola online, o $1429^{\circ}$ lugar. Mesmo tendo um decréscimo no decorrer dos anos, apresenta grandes números de tiragem, inclusive aumentando em 2013 (9,9\%), um ano de grande crise para o setor publicitário, sendo a revista Nova Escola, na lista de mensais, a que obteve mais aumento de tiragem (GUIMARÃES, 2013). Os editores de "Nova Escola" destacam em página da Revista na Internet, "nossa missão é fortalecer o educador para transformar o Brasil. Para isso, desenvolvemos produtos e serviços de excelência que valorizam os professores, facilitam seu dia-a-dia e apoiam sua

\footnotetext{
${ }^{2}$ As horas dedicadas ao estudo docente recebe diversas denominações nas redes de ensino, sendo as mais comuns Hora de Trabalho Coletivo (HTPC) e Atendimento Pedagógico Coletivo (ATPC).
} 
carreira" (ASSOCIAÇÃO NOVA ESCOLA, 2018b). Os números e a missão institucional da revista nos remetem a compreender que Nova Escola está presente no cotidiano de muitos professores subsidiando o trabalho pedagógico.

\section{A revista "Nova Escola" como objeto de pesquisa: caminho percorrido}

Ao realizarmos um levantamento de estudos que tiveram a Revista Nova Escola como objeto de pesquisa, encontramos diversos trabalhos que abordam temáticas similares, dentre eles, destacamos Costa (2003), Morrone (2003) e Stumpf (2003), indicando que a revista é um contundente objeto de pesquisa, análise, reflexão.

Atualmente, a revista Nova Escola faz parte da Associação Nova Escola, criada em 2015, que se apresenta como uma organização sem fins lucrativos cuja mantenedora é a Fundação Lemann: "Nossa missão é transformar a Educação brasileira por meio de conteúdos e serviços de alta qualidade para professores e gestores do Brasil" (ASSOCIAÇÃO NOVA ESCOLA, 2018a).

A partir de então, a assinatura da revista passou a ter um valor monetário maior, sendo o processo de compra realizado basicamente pelo seu site, proporcionando formas diversas de aquisição. A revista também não é mais encontrada em bancas de jornais, é somente entregue a assinantes, dificultando a aquisição esporádica, além de as escolas públicas não mais receberem os exemplares gratuitamente.

A página online da revista oferece diversos serviços, principalmente para os assinantes, dentre eles, planos de aula por faixa etária e disciplinas, cursos, blogs, concursos, vídeos, dentre outros.

Antes de 2015, a Revista pertenceu, por trinta anos, à Editora Abril e era organizada pela Fundação Victor Civita. Segundo editores, a revista era comercializada a preço de custo, devido a uma parceria entre a editora, o Ministério da Educação (MEC) e também iniciativas particulares, garantindo 
distribuição gratuita a algumas instituições educacionais (ASSOCIAÇÃO NOVA ESCOLA, 2018a).

A revista Nova Escola, desde sua publicação inicial, conta com dez números anuais, não circulando nos meses de janeiro e julho, havendo no decorrer do ano alguns números/ edições especiais e específicas.

No decorrer dos anos, a revista apresentou slogans marcantes, dentre eles destacamos: "A Revista do Professor" e a "Revista de quem Educa", sem contar no prêmio intitulado "Professor Nota 10", caracterizando assim o público a que se destina.

Os editores de "Nova Escola", anteriores e atuais, destacam que a revista tem como princípio e meta auxiliar os professores do país. Analisando diversos artigos da revista percebemos que é constante a concepção de que o professor é capaz de solucionar por si próprio todas as questões adversas de sala de aula, bastando para tanto ter compromisso, dedicação, determinação e pouco se questionam os diversos aspectos políticos, sociais e mesmo administrativos que são enfrentados no cotidiano das salas de aula.

Podemos assim considerar a revista Nova Escola um divulgador de comunicação, integrante dos artefatos culturais, que propaga ideias, valores, concep̧̧ões de seus produtores e leitores; assim nos depreendemos com a indagação: como a revista Nova Escola vem contribuindo no decorrer dos anos para a consolidação da educação sexual no tocante à apresentação de reportagens sobre as temáticas sexualidade e gênero? Essa questão é suscitada devido, como mencionado, a temática da sexualidade ainda possuir lacunas no contexto escolar, inclusive no que tange à formação docente.

Deste modo, traçamos para esse artigo os seguintes objetivos: mapear e analisar os artigos das temáticas da sexualidade e gênero presentes na revista Nova Escola no período de 2000 a 2017, bem como estabelecer uma interface do conhecimento sexual e consolidação da educação sexual no contexto escolar.

Depreendemos que analisar a temática da sexualidade e gênero apresentados na revista Nova Escola, torna-se algo instigante e capaz de 
apresentar caminhos diversos para pesquisas, questionamento e mesmo considerações.

Apresentada a revista Nova Escola como nosso objeto de pesquisa, fezse necessário determinar o período a ser analisado e a forma como será desenvolvida a busca e análise. Optamos por iniciar a pesquisa pelo ano de 2000, pois tendo a implantação dos Parâmetros Curriculares Nacionais $(\mathrm{PCN})$, especificamente o tema transversal orientação sexual, como documento norteador de muitos estudos e propostas curriculares (BRASIL, 1997, 1998a). É de consenso escolar que os/as docentes também precisam conhecer a temática do documento para trabalhar em sala de aula, e a revista, com o caráter de auxiliar o docente, pressupõe-se que também abordará o assunto.

Determinado o período a ser trabalhado, o próximo passo foi a decisão sobre como fazer a busca. O primeiro momento do trabalho foi marcado pela procura da revista Nova Escola em bibliotecas, escolas, sebos, sendo que alguns exemplares não foram encontrados ${ }^{3}$.

Posteriormente, foi realizada a verificação dos títulos das reportagens que apresentassem as palavras sexualidade, gravidez, sexo, educação sexual, orientação sexual, homossexualidade, gênero, feminino/masculino/homem/mulher ${ }^{4}$ e ensino de ciências.

Em um terceiro momento, partimos para realização da leitura dos artigos completos, destacando pontos relevantes que foram abordados e analisados. Como forma de melhor organização e para se ter uma visão geral dos artigos pesquisados, elaboramos uma tabela com a síntese de dados relevantes, pois o contexto pesquisado consta com 158 revistas, sendo que desse universo foram encontrados 45 artigos para análise e discussão, ou seja, um percentual de 29\% aproximadamente de artigos com a temática estudada.

\footnotetext{
${ }^{3}$ Não foram encontradas 23 revistas.

${ }^{4}$ Quando surgiram palavras próximas como, por exemplo, menino/menina, aluno/aluna, a seleção foi feita a partir das palavras chaves do resumo, no caso se houvesse as palavras apresentadas no critério de seleção dos títulos.
} 
Quadro 1: Relação das Revistas com a temática abordada/Síntese dos artigos analisados

\begin{tabular}{|c|c|c|c|}
\hline $\begin{array}{l}\text { Ano de } \\
\text { Publicaçã }\end{array}$ & $\begin{array}{l}\text { Número } \\
\text { Revistas } \\
\text { analisadas }\end{array}$ & $\begin{array}{l}\text { Número/mês das Revista: } \\
\text { que } \\
\text { foram encontrados artigc } \\
\text { sobre a Temática sexo/ } \\
\text { Sexualidade/ Gênero }\end{array}$ & Síntese dos Temas abordados \\
\hline 2000 & 07 & $\begin{array}{l}08 \text { artigos encontrados } \\
\text { /fev./mar/abr./ } \\
\text { maio/ set/out/nov. }\end{array}$ & $\begin{array}{l}\text { _ Doenças Sexualmente Transmissíveis (DST); } \\
\text { _ Mudanças hormonais na adolescência; } \\
\text { _ Reprodução; } \\
\text { _Menstruação;Masturbação; } \\
\text { _ Namoro / gravidez precoce. }\end{array}$ \\
\hline 2001 & 09 & 01 artigo encontrado /abr. & $\begin{array}{l}\text { - AIDS; } \\
\text { _ Abuso sexual; } \\
\text { Homossexualidade. }\end{array}$ \\
\hline 2002 & 07 & Não encontrado & \\
\hline 2003 & 08 & $\begin{array}{l}02 \text { artigos encontrados } \\
\text { ago./jun. }\end{array}$ & $\begin{array}{l}\text { _ Masturbação Infantil. } \\
\text { _ Educação Sexual/ capacitação docente }\end{array}$ \\
\hline 2004 & 09 & $\begin{array}{l}02 \text { artigos encontrados / } \\
\text { abr./jun. }\end{array}$ & _ Gênero; educação sexual. \\
\hline 2005 & 09 & Não encontrados & \\
\hline 2006 & 07 & $\begin{array}{l}02 \text { artigos encontrados/ } \\
\text { abr./dez. }\end{array}$ & $\begin{array}{l}\text { _ Educação Sexual; } \\
\text { _ Gênero. }\end{array}$ \\
\hline 2007 & 09 & $\begin{array}{l}02 \text { artigos encontrados/ } \\
\text { jun./nov. }\end{array}$ & - Gênero \\
\hline 2008 & 10 & $\begin{array}{l}03 \text { artigos encontrados/ } \\
\text { maio/ago. }\end{array}$ & $\begin{array}{l}\text { _ Gravidez precoce; } \\
\text { _ Educação Sexual. }\end{array}$ \\
\hline 2009 & 08 & $\begin{array}{l}02 \text { artigos encontrados } \\
\text { Fev./maio }\end{array}$ & $\begin{array}{l}\text { _Gênero; } \\
\text { _Homofobia. }\end{array}$ \\
\hline 2010 & 07 & $\begin{array}{l}02 \text { artigos encontrados/ } \\
\text { fev./abr. }\end{array}$ & $\begin{array}{l}\text { _ Contatos afetivos; } \\
\text { _ Relações de gênero; } \\
\text { _ Dúvidas sobre sexualidade na } \\
\text { infância/adolescência. }\end{array}$ \\
\hline 2011 & 10 & 01 artigo encontrado/ nov. & $\begin{array}{l}\text { _ Corpo e sexualidade; } \\
\text { - Valorização da educação sexual desde tenra } \\
\text { idade. }\end{array}$ \\
\hline 2012 & 10 & 01 artigo encontrado/ maio & _ Gênero. \\
\hline 2013 & 10 & $\begin{array}{l}02 \text { artigos encontrados/ } \\
\text { maio/nov. }\end{array}$ & $\begin{array}{l}\text { _ Gênero; } \\
\text { _ Abuso Sexual }\end{array}$ \\
\hline 2014 & 09 & $\begin{array}{l}4 \text { artigos encontrados/ } \\
\text { abr./jun./out. }\end{array}$ & $\begin{array}{l}\text { - Internet e sexting; } \\
\text { _AIDS; } \\
\text { - Orientação Sexual; } \\
\text { _ Gênero. }\end{array}$ \\
\hline 2015 & 09 & $\begin{array}{l}02 \text { artigos encontrados/ } \\
\text { fev./out. }\end{array}$ & $\begin{array}{l}\text { _ Preconceito; } \\
\text { _ Gênero; } \\
\text { _ Homossexualidade; } \\
\text { _LGBT. }\end{array}$ \\
\hline 2016 & 10 & $\begin{array}{l}06 \text { artigos encontrados/ } \\
\text { fev./mar./ago./Set. }\end{array}$ & $\begin{array}{l}\text { _ Gênero; } \\
\text { _ Inclusão/homofobia; } \\
\text { _Diversidade;exual; } \\
\text { _ Gravidez na adolescência. }\end{array}$ \\
\hline
\end{tabular}




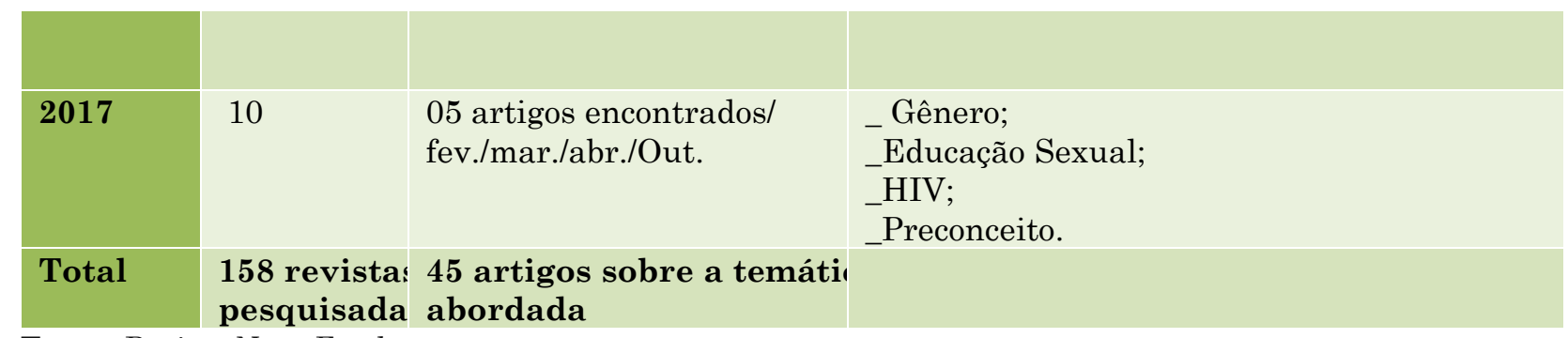

Fonte: Revista Nova Escola.

A partir da leitura dos artigos encontrados no corpus pesquisado foi realizada a análise dos dados de forma qualitativa, com base na Análise Temática proposta por BARDIN (1977). Para a autora "[...] tema é a unidade de significação que se liberta naturalmente de um texto analisado, segundo critérios relativos à teoria que serve de guia à leitura” (BARDIN, 1977, p. 105).

Laville e Dione (1999) destacam que a Análise de Conteúdo não se caracteriza por ser um método rígido, no sentido de um receituário com etapas pré-determinadas. É possível o pesquisador construir unidades de análises a partir de sua compreensão, sempre seguindo critérios científicos e o contexto em que os "elementos" aparecem.

Assim, ao realizar uma análise temática, é necessário reconhecer núcleos de sentido, que são manifestos devido à frequência ou à própria presença, apresentando significação para o objeto em estudo.

Após a leitura dos textos, construímos um contato exaustivo com o material coletado, elaborando pressupostos, palavras-chave e recortes capazes de proporcionar a categorização do material em questão para análise fundamentando nos estudos sobre sexualidade e gênero que embasam a pesquisa. Apresentamos no quadro 2 os dados mais significativos encontrados nas reportagens.

Quadro 2: Análise temática: temas abordados nas Revistas pesquisadas

\begin{tabular}{l|l|c|} 
Categorias & Subcategorias & Número de ocorrência \\
\hline Educação Sexual & DST/ adolescência/ reprodução/namoro / & 37 \\
& gravidez precoce/ abuso sexual/homofobia/ &
\end{tabular}




\begin{tabular}{|c|c|c|}
\hline & $\begin{array}{l}\text { corpo/preconceito/sexualidade infantil/ } \\
\text { capacitação docente }\end{array}$ & \\
\hline Gênero & $\begin{array}{l}\text { Homossexualidade/capacitação docente/ } \\
\text { orientação sexual/ preconceito/ LGBT/ } \\
\text { diversidade sexual }\end{array}$ & 26 \\
\hline
\end{tabular}

Fonte: Revista Nova Escola.

A análise realizada no período estipulado possibilitou a identificação de duas categorias, Educação Sexual e Gênero, seguidas de subcategorias de acordo com os assuntos mais recorrentes nos artigos.

A análise qualitativa dos dados buscou compreender e considerar os resultados encontrados em cada reportagem analisada, pois como afirma Minayo (2000), a pesquisa qualitativa trabalha com um universo de significações. A autora ainda adverte que as relações entre abordagens qualitativas e quantitativas demonstram que as duas metodologias não são incompatíveis e podem ser integradas num mesmo projeto. Assim, as ocorrências das categorias/ subcategorias terão o propósito de apresentar, com maior clareza, dados como um todo do período estudado.

\section{Discussões sobre Educação Sexual e Gênero na revista Nova Escola}

Constatamos que a revista Nova Escola tem um número elevado de tiragens, o que colabora para sua popularização no meio educacional, seu vocabulário de fácil entendimento e mesmo o caráter de "final feliz" das reportagens apontam ímpetos de transparecer que a educação é algo que ocorre de maneira simplificada e que cabe principalmente à boa vontade docente para que ações de sucesso ocorram. Há várias ilustrações que culminam para chamar atenção do leitor de modo a ilustrar os temas e facilitar a leitura. Conforme assinala Bueno:

Enquadrado como mais um entre os estereótipos da sociedade de massas, o professor [...], vê-se anulado como um sujeito universal capaz de pensar o todo. Desincumbido de sua especificidade, ao professor resta apenas o 
consumo distraído de fórmulas que o põem em sintonia uma totalidade que assim permanece imune à crítica. (BUENO, 2007, p. 304).

Verificamos que Nova Escola apresenta a discussão da temática de gênero de diversas maneiras, desde a educação infantil ao ensino médio, apresentando a carreira docente com rotinas desiguais entre os sexos, inclusive no magistério ${ }^{5}$. Os depoimentos são pouco questionadores sobre a sociedade androcêntrica em que vivemos e o sacrifício das mulheres pelas várias jornadas de trabalho e estudo é visto como sendo recompensado, pois a força do feminino se sobrepõe e é capaz de superar as mazelas da sociedade.

Ensinaram-me que casamento é para sempre e que mulher tem de ser donade-casa. Por isso, só pude concluir o Ensino Superior no ano passado, aos 38 anos. Comecei a carreira aos 15. Em 1988, um projeto do governo estadual me habilitou a dar aulas de $5^{\text {a a }} 8^{\text {a }}$. Casei um ano depois e em 1991 veio meu primeiro filho. Parei de estudar e, para sustentar a casa encarava uma tripla jornada. [...]. Estudei muito, tive crises nervosas, me alimentava mal e não tinha tempo para meus filhos. Hoje, fico mais com os meninos e me permito descansar. Relato de Divina Aparecida Pereira da Silva Hunhoff, professora de $5^{\mathrm{a}}$ a $8^{\mathrm{a}}$ série de matemática e ciências em Alexânia (GO). (CAVALCANTE, 2006, p. 35).

\section{$[\ldots]$}

Criar condições justas de trabalho e salário é um dos grandes desafios da Educação. A questão de que existem espaços diferenciados para homens e mulheres pode ser observada até nas universidades, onde o professorado feminino soma $42 \%$, mas está concentrado principalmente em cursos de Pedagogia, Letras e Enfermagem. (CAVALCANTE, 2006, p. 36).

Há mais de dez anos da reportagem citada anteriormente, ainda é possível perceber que a profissão docente se constitui majoritariamente feminina, e muitas vezes ainda tem o ideário da afirmação de Mello (1981, p.

\footnotetext{
${ }^{5}$ Exemplos das reportagens "Rotina Desigual" (CAVALCANTE, 2006) e "Sala de aula sem preconceito" (MORO, 2004).
} 
70) mencionada na década de 1980, pois “a condição feminina é um dos elementos que garantem a perpetuação do senso comum, no qual predominam o amor, a vocação e a ausência de profissionalismo".

É preciso compromisso com a docência e concebê-la enquanto profissão, inclusive fortalecendo todo o seu valor social diante da própria atualidade e da formação das novas gerações, fato que também precisa ser aludido pelos artefatos culturais. A revista Nova Escola, neste artigo em específico, é capaz de propor a reflexão, pois apresenta a mulher além do estereótipo social de incapaz, que assume inciativa pela própria vida, colaborando, mesmo sem apresentar discussões, para abordar a temática de gênero indo além do padrão tradicional, dicotômico de homem e mulher.

Os sujeitos que constituem a dicotomia não são, de fato, apenas homens e mulheres, mas homens e mulheres de várias classes, raças, religiões, idades, etc. e suas solidariedades e antagonismos podem provocar os arranjos mais diversos, perturbando a noção simplista e reduzida de "homem dominante versus mulher dominada". Por outro lado, não custa reafirmar que os grupos dominados são, muitas vezes, capazes de fazer dos espaços e das instâncias de opressão, lugares de resistência e de exercício de poder. (LOURO, 1997, p. $33)$.

Vivemos em uma sociedade em que os homens ainda ocupam posição privilegiada, influenciando na valorização profissional. O magistério ainda é prioritariamente ocupado por mulheres, possuindo dificuldade em construir sua identidade profissional. A docência é acumulada, geralmente, com o trabalho doméstico em casa ou nos cuidados com a família, fato que atribui as mulheres jornadas exaustivas de trabalho diário. Muitas professoras são as provedoras financeiras da família. Esse fato é contraditório com a ideia prevalente de que a profissão docente está relacionada à vocação, meiguice e cuidados envoltos com à maternidade.

A reportagem de 2004, "Sala de aula sem preconceito" (MORO, 2004), traz a temática das mulheres na ciência, abordando a discriminação de gênero 
em carreiras consideradas mais prestigiadas e mesmo as relações cotidianas na sala de aula, propondo reflexões pedagógicas para as ações docentes.

Como causa ou consequência da menor participação das mulheres no mundo científico, o ensino de Ciências e de Matemática tem sido alvo de estudos que mostram a existência dessa discriminação desde a sala de aula, "[...] é interessante pesquisar com toda a classe as contribuições históricas e os desafios enfrentados pelas mulheres para uma maior participação na ciência." (MORO, 2004, p. 21).

Os pontos destacados pela reportagem são relevantes, além de fazerem parte dos temas transversais que constituem os Parâmetros Curriculares Nacionais (BRASIL, 1997,1998a).

Os estudos de gênero perpassam os blocos de conteúdo dos PCN (BRASIL,1998a, 2001), pois “[...] A discussão sobre relações de gênero tem como objetivo combater relações autoritárias, questionar a rigidez dos padrões de conduta estabelecidos para homens e mulheres e apontar para sua transformação [...]" (BRASIL, 2001, p. 144). Atualmente, a Base Nacional Comum Curricular (BRASIL, 2017) faz apontamentos, embora elementares, sobre gênero. Consideramos que inclusa nas competências estabelecidas para a educação infantil e ensino fundamental, abordar a temática é fundamental, pois

[...] requer que a instituição escolar seja deliberadamente aberta à pluralidade e à diversidade, e que a experiência escolar seja acessível, eficaz e agradável para todos, sem exceção, independentemente de aparência, etnia, religião, sexo, identidade de gênero, orientação sexual ou quaisquer outros atributos, garantindo que todos possam aprender. Dessa maneira, a equidade reafirma seu compromisso de reverter a situação de exclusão histórica. (BRASIL, 2017, p. 11). 
A forma como homens e mulheres agem no cotidiano social é fruto de aprendizado sociocultural, cabendo também aos espaços educativos proporcionarem questionamentos e intervenções em atitudes ou manifestações que provoquem violência ou repúdio a padrões tidos como majoritários. Desse modo os artefatos culturais produzem mediante discursos e imagens a constituição de significados, direcionando determinadas posturas inclusive no ser e se constituir professor.

As sutis brincadeiras no pátio da escola, as falas corriqueiras em salas de aula, a reprodução sem reflexão dos ditos populares, piadas consideradas inofensivas, podem desencadear concepções que se tornam arraigadas no sentido de desvalorização e inferioridade da mulher, seria a opressão que gera violência e subordinação.

O espaço escolar poderia ir muito além de trabalhar com dicotomias, divisões de sexo, pois percebe-se que na sociedade, atualmente, mesmo diante de diversos avanços dos movimentos feministas e de diversidade sexual, permanece a valorização do masculino.

Desse modo, a docência, enquanto profissão, representada majoritariamente pelo feminino, torna-se fragilizada, fator que também precisa ser discutido nos cursos de formação, tanto da Pedagogia como das demais licenciaturas e, consequentemente nos artefatos culturais, principalmente os destinados à classe docente, em específico.

A revista Nova Escola também é utilizada nos cursos de formação docente; seus artigos não precisam ser concebidos como o "modelo ideal" ou "politicamente correto", mas são capazes de provocar constantemente em seus leitores reflexões sobre a influência dos artefatos culturais, fatores que deve ser despertado e discutidos desde os cursos de formação. Apreendemos que atualmente os cursos de licenciatura devem investir no aprofundamento sobre a complexidade da relação pedagógica, bem como na formação de um professor atento e crítico às relações de poder emanadas pelos artefatos culturais. 
Outro aspecto destacado na análise dos artigos de Nova Escola referese à abordagem sobre gênero e diversidade sexual, que são apresentados muitas vezes de maneira pouco evidente, outras apontando diferenças de comportamentos $^{6}$, ou ainda sem desmistificação do tema. Em contrapartida, alguns textos trazem apontamentos significativos em torno do próprio currículo oculto e os preconceitos existentes no âmbito da escola, em todos os níveis de escolarização ${ }^{7}$. Podemos citar o exemplo o texto de Peres (2016).

\begin{abstract}
Afirmar que as meninas devem "se dar ao respeito". Ideias assim jogam a culpa pelo assédio na vítima. Não force as meninas a se encaixar em um modelo de comportamento "adequado". Em vez disso, converse com os meninos sobre a necessidade de respeitar todas as mulheres, sem exceção. Quando é preciso convencer as meninas sobre o feminismo. (PERES, 2016, p. 32, 38, grifo nosso).
\end{abstract}

Conforme destacamos, os subtítulos e o texto são relevantes, contudo fazem apontamentos somente pontuais em relação à temática de gênero e às questões da orientação sexual, não oferecendo nenhum outro tipo de subsídio didático para que o professor e/ou a equipe gestora possam recorrer para sistematizar e referenciar melhor o trabalho de orientação. Vale destacar que os familiares podem ter opiniões contrárias ao desenvolvimento dessas atividades escolares e isso é um fator de preocupação dos docentes e gestores. Geralmente, essas situações são tratadas de forma ambígua e obliterante, sendo necessário um suporte técnico-pedagógico para que as situações que envolvem a temática sejam guiadas de forma satisfatória.

Consideramos que a revista deixa a desejar no tocante a forma de abordagem e discussão, contemplando a diversidade, o reconhecimento das políticas públicas e mesmo os documentos pedagógicos que contribuem com tal discussão, que precisa ser colocada em evidência.

\footnotetext{
6 "Isso é machismo. E Precisa acabar" . "As meninas que estão mudando a escola" (PERES, 2016).

7 "Brincadeira não tem sexo" (BENCINI, 2007).
} 
Defendemos que é necessário respeitar a diversidade de valores, crenças e comportamentos existentes e relativos à sexualidade, desde que seja garantida a dignidade do ser humano: "[...] reconhecer como determinações culturais as características socialmente atribuídas ao masculino e ao feminino, posicionando-se contra discriminações a eles associadas" (BRASIL, 2001, p.133).

Também é preciso compreender que a docência e a educação não podem ser constituídas por achismos e que exemplos de outras instituições são louváveis de reconhecimento, mas não podem ser aplicados na íntegra. Cada escola tem sua particularidade social e cultural e, portanto, abordar a cientificidade que envolve o tema é fundamental.

Em reportagem relacionada à educação infantil (2007), diferentemente da mencionada anteriormente, a autora apresenta questões a serem desenvolvidas no cotidiano escolar, inclusive na faixa etária da educação infantil, na qual os jogos de imitação são corriqueiros, fato que corrobora com o Referencial Curricular da Educação Infantil (BRASIL, 1998b), e se relacionam com a temática de gênero, sendo leitura fundamental para os profissionais que atuam com essa faixa etária. "Trabalhar esses padrões e expectativas é função do professor porquê disso depende também a construção da identidade dos pequenos. Essa tarefa se cumpre nas relações do dia-a-dia e não por meio de um projeto esporádico ou de uma sequência didática." (BENCINI, 2007, p. 104).

Hoje, se a maioria das crianças e adolescentes passam maior parte da infância e da juventude na escola, o aprendizado em torno da concepção de gênero é fundamental nesse espaço. Ademais, compreender o conceito de gênero e suas facetas, quais sejam, os processos de discriminação, de diferenciação entre os sexos, a violência em torno das questões femininas e masculinas, dentre outros, pode ajudar a criar-se um olhar mais atento e criterioso aos processos em que se consolidam as diferenças e as situações preconceituosas, buscando construir assim a equidade de gênero. 
Oferecer às crianças oportunidade de viver diferentes papéis, contribui para a construção da identidade, tema a ser trabalhado no dia-a-dia e não necessariamente em um projeto específico. Trabalhar questão de gênero mostra que meninos e meninas têm direitos iguais. [...] Promove integração de ambos os sexos. (BENCINI, 2007, p. 104).

Assim podemos pressupor que a escola não é um espaço isolado da sociedade. Esse fator deve ser consubstanciado pelo processo formativo, pois a sua atuação não é neutra, tem grande influência no pensamento e nas ações dos/as discentes.

A inscrição dos gêneros - femininos ou masculinos - nos corpos é feita, sempre, no contexto de uma determinada cultura e, portanto, com as marcas dessa cultura. As possibilidades da sexualidade das formas de expressar os desejos e prazeres - também são sempre socialmente estabelecidas e codificadas. As identidades de gênero e sexuais são, portanto, compostas e definidas por relações sociais, elas são moldadas pelas redes de poder de uma sociedade. (LOURO, 2010, p. 11).

Essa compreensão demanda atuar na práxis pedagógica, ir além do instituído e propor a reflexão a partir da própria ação. É notório desconstruir e desnaturalizar as polaridades masculino/feminino, heterossexual/homossexual, problematizando e questionando as diferenças decorrentes nos diversos espaços sociais.

Ao abordar as temáticas da diversidade sexual e transgêneros, uma das edições da revista apresentou na capa um garoto britânico vestido com a roupa da personagem Pequena Sereia, ${ }^{8}$ essa capa foi eleita a melhor do ano por um concurso promovido pela Associação Nacional dos Editores de Revistas. Acreditamos que muitos/as garotos/as brasileiros/as passam pelo

\footnotetext{
8 "Precisamos falar sobre Romeo" (SOARES, 2015).
} 
mesmo desfecho do garoto britânico e poderiam ser a foto da capa. Acreditamos que este fato poderia valorizar o contexto da escola brasileira, que apesar de estar passando por transformações, ainda carrega muitos preconceitos em relação ao tema. Contudo, sabemos dos limites que cercam a produção do jornalismo para conseguir exemplos brasileiros sobre a questão.

$\mathrm{Na}$ mesma reportagem, os docentes não têm opiniões explicitadas. $\mathrm{O}$ texto apresenta experiências bem-sucedidas geralmente iniciadas pelos alunos, mas também marcadas por procedimentos determinados dos responsáveis do contexto escolar. Assim, mais uma vez, transparece a ideia de que enfrentar a questão é fruto de determinação e vontade dos envolvidos.

O caso de Clarke (nome do garoto da capa) não é único. Situações em que crianças e jovens que descumprem as regras socialmente aceitas sobre ser homem ou mulher - seja de forma intencional ou por não dominá-las - fazem parte da rotina escolar. Quando eclode o machismo, a homofobia ou o preconceito aos transgêneros, pais e professores agem rápido para pôr panos quentes e, sempre que possível, fazer de conta que nada ocorreu. Paradoxalmente, quem tem ensinado a escola a agir no respeito à diversidade são os próprios estudantes. É papel da escola agir com profissionalismo. (SOARES, 2015, p. 25).

A reportagem traz fotos de página inteira ilustrando casos em que alunos/as não tiveram sua orientação sexual ou mesmo sua própria identidade respeitada no espaço escolar; as imagens reforçam o assunto tratado, como um atrativo para a leitura.

Fator a se destacar refere-se à abordagem quanto à formação docente e o compromisso por parte das políticas públicas, contudo a atuação, opinião, participação docente não é colocada em questão, somente três parágrafos da reportagem são destinados a isso, ou seja, indicações de como a escola e docentes "poderiam" agir, uma espécie de prescrição. 
A instituição deve ser um ambiente em que todos os alunos se sintam acolhidos. [...] É preciso deixar de naturalizar esse tipo de episódio (referente ao assédio de meninos e meninas). Meninos precisam respeitar o corpo da mulher. Cantadas desrespeitosas e situações de assédio podem ser comuns, mas não são aceitáveis [...]. Questionar desde a Educação Infantil as normas e os padrões associados a cada um dos gêneros são um passo inicial. A definição do que é roupa de meninas e o que é roupa de menino também é feita por convenções que variam de acordo com a cultura e o local. (SOARES, 2015, p. 27, 29, 31).

O contexto escolar é espaço profícuo para a educação sexual e a revista Nova Escola destaca essa abordagem em vários artigos ${ }^{9}$. Aponta, dentre outros, os livros didáticos e o currículo como pontos cruciais nessa proposta que carece de conhecimento. Contudo é fundamental destacar que a as condições de trabalho, as várias jornadas que incapacitam os estudos não são questionadas, nem mesmo o empoderamento político e cultural que precisam ser vistos como motivos de amarras para uma educação sexual emancipatória.

Desde que se tornou uma sugestão dos Parâmetros Curriculares Nacionais, a inclusão do tema Educação Sexual de forma transversal nas disciplinas escolares tem atormentado o cotidiano de muitos professores e coordenadores de ensino. [...] Para você se tornar apto a vestir essa camisa, uma sugestão é buscar conteúdo em livros e outras publicações. Outro passo é participar de palestras, oficinas e cursos. (MULLER, 2003, p. 16).

Crianças e adolescentes estão descobrindo a sexualidade e os limites do próprio corpo. Veja aqui como ajudá-los a enfrentar essa fase tão importante da vida sem mitos nem atropelos (tanto em casa como na escola). (GENTILE, 2006, p. 22)

\footnotetext{
9 "É preciso falar de sexo" (MULLER, 2003) e "Eles querem falar de sexo" (GENTILE, 2006).
} 
A formação docente ainda apresenta muitas brechas no tocante à educação sexual. Consequentemente, mitos, atropelos e contradições podem surgir nas aulas. Assim, a educação sexual adentra o contexto escolar muito distante da conscientização crítica do indivíduo para exercer sua sexualidade de maneira responsável e congruente, rompendo tabus e preconceitos. Segundo Nunes e Silva (2000), a Educação Sexual Emancipatória compreende a formação plena e integral do ser humano, em um contexto histórico, pois se trata de uma construção ético-social.

O conceito de educação sexual emancipatória contrapõe-se ao sentido de alienação, indo ao encontro de orientação, de se sentir integrante do processo cultural/social, do integrar-se ao mundo, da sensatez, sendo de modo sucinto vinculada ao valor inigualável do ser humano enquanto pensante e capaz de refletir sobre suas atitudes com alteridade.

Percebemos que as reportagens de Nova Escola, mesmo abordando temáticas significativas para a educação sexual e questionando aspectos da formação docente, não levantam suspeitas sobre seu caráter de receituário ao abordar sexualidade e gênero, pois centra-se somente em experiências pontuais e significativas que deram resultados esperados, transmitindo ao leitor a visão de que sempre é possível um "final feliz" em relação ao tema.

\section{Considerações finais}

Ao analisarmos a produção da revista Nova Escola sobre sexualidade e gênero, nos deparamos com artigos que abordam assuntos variados que podem enriquecer o aprendizado e a prática docente, bem como as experiências construídas no cotidiano das escolas.

Para tanto, é preciso que os educadores percebam os limites da produção jornalística destinada aos docentes. Dentre esses limites podemos apontar a linguagem simplificada, textos com caráter prescritivo, valorização de "modismos e inovações pedagógicos", e a aposta exagerada no empenho dos 
docentes para achar a solução para os problemas pedagógicos, culturais e sociais que abrangem a prática educativa.

Conforme apontado, a revista Nova Escola está presente nos cursos de formação docente. Precisamos compreender a revista como provedora de saberes, culturas e aprendizagens que podem complementar e se articular a formação contínua da docência. Sem dúvidas, esse artefato é capaz de propor informação e de fazer pensar sobre sexualidade e gênero. Mas é preciso ir além. É preciso superar a ideia do consumidor voraz de notícias, de experiências e novidades. Ultrapassar a ideia de que a formação se dá pela leitura rápida, pronta e fortemente ilustrada por imagens. É preciso buscar o aprofundamento necessário que a temática exige e isso é insuficiente na publicação analisada.

\section{Referências}

ASSOCIAÇÃO NOVA ESCOLA. Nossa história. Disponível em: < https://novaescola.org.br/quem-somos >. Acesso em: 16 jun. 2018a.

ASSOCIAÇÃO NOVA ESCOLA. Quem somos. Disponível em: < https://novaescola.org.br/quem-somos >. Acesso em: 16 jun. $2018 \mathrm{~b}$.

BARDIN, Laurence. Análise de conteúdo. Tradução de Luís Antero Reto e Augusto Pinheiro. Lisboa: Edições 70, 1977.

BENCINI, Roberta. Brincadeiras não tem sexo. Nova Escola, São Paulo,n. 203, p. 104-107, jun./jul. 2007.

BRASIL. Ministério da Educação e do Desporto. Secretaria de Educação Fundamental. Base Nacional Comum Curricular. Proposta preliminar. Brasília: MEC, 2017. Disponível em: < http://basenacionalcomum.mec.gov.br/images/BNCCpublicacao.pdf $>$. Acesso em: 29 ago. 2017.

. Parâmetros curriculares nacionais: pluralidade cultural: orientação sexual. Brasília: A Secretaria, 2001.

. Parâmetros curriculares nacionais: terceiro e quarto ciclos: apresentação dos temas transversais. Brasília: MEC/SEF, 1998a. 1998b.

Referencial curricular nacional para a educação infantil. Brasília: MEC/SEF, 
. Parâmetros Curriculares Nacionais: introdução aos Parâmetros Curriculares Nacionais. Brasília: MEC/SEF, 1997.

BUENO, Sinésio Ferraz. Semicultura e educação: uma análise crítica da revista Nova Escola. Revista Brasileira de Educação, Rio de Janeiro, v. 12, n. 35, p. 300-307, maio/ ago. 2007.

CAVALCANTE, M. Rotina desigual. Nova Escola, São Paulo, n. 198, p. 36-38, dez. 2006.

COSTA, Gilcelene Dias da. Entre a política e a poética do texto cultural: a produção das diferenças na revista Nova Escola. 2003. 136 f. Dissertação (Mestrado em Educação) -Universidade Federal do Rio Grande do Sul, Faculdade de Educação, Porto Alegre, 2003.

GENTILE, Paola. Eles querem falar de sexo. Nova Escola, São Paulo, n. 191, p. $22-$ 29, abr. 2006.

GUIMARÃES, K. Impresso se reestrutura após quedas. Jornais e revistas citam 2013 como "ano difícil'; conteúdo e digital são tendências. 23/12/2013. Disponivel em:< http://propmark.com.br/midia/impresso-se-reestrutura-apos-quedas $>$. Acesso em: 22 abr. 2016.

LAVILLE, Christian; DIONNE, Jean. A construção do saber: manual de metodologia da pesquisa em ciências humanas. Tradução de H. Monteiro, F.Settineri, Porto Alegre: Artmed, 1999.

LARROSA BONDÍA, Jorge; KOHAN, Walter. Apresentação da Coleção. In: RANCIÈRE, Jacques. O mestre ignorante. Belo Horizonte: Autêntica, 2002.

LOURO, Guacira Lopes. Gênero, sexualidade e educação: uma perspectiva pósestruturalista. Petrópolis: Vozes, 1997.

. Pedagogias da Sexualidade. In: LOURO, Guacira Lopes. (Org.). O corpo educado: pedagogia da sexualidade. Belo Horizonte: Autêntica editora, 2010. p. 7-34.

MELLO, Guiomar Namo de. Magistério de $1^{o}$ grau: da competência técnica ao compromisso político. São Paulo: Cortez, 1981.

MINAYO, Maria Cecília.de S. O desafio do conhecimento: pesquisa qualitativa em saúde. São Paulo: Hucitec, 2000.

MORO, Claudia Cristine. Sala de aula sem preconceito. Nova Escola, São Paulo, n. 171, p. 21, abr. 2004.

MORRONE, Maria Lúcia. Revista Nova Escola: discursos, representações e prescrições pedagógicas no ensino de História (1986-1995). 2003. 302 f. Tese (Doutorado em Educação) - Pontifícia Universidade Católica, Faculdade de Educação, São Paulo, 2003. 
MULLER, Laura. É preciso falar de sexo. Nova Escola, São Paulo, n. 164, p.16, ago. 2003.

NUNES, César Aparecido; SILVA, Edna Aparecida. A educação sexual da criança: subsídios teóricos e propostas práticas para uma abordagem da sexualidade para além da transversalidade. Campinas: Autores Associados, 2000. (Coleção polemicas do nosso tempo; 72).

PERES, Paula. Isso é machismo e precisa acabar. As meninas que estão mudando a escola. Nova Escola, São Paulo, n. 295, p. 32-40, set. 2016.

PETRENAS, Rita de Cássia. O estado da arte sobre as temáticas sexualidade, educação sexual e gênero nos encontros nacionais de didática e práticas de ensinoENDIPE (1996-2012). Tese (Doutorado em Educação Escolar) - Universidade Estadual Paulista, Faculdade de Ciências e Letras, Campus de Araraquara, 2015.

RIBEIRO, Paulo Rennes Marçal. A sexualidade na história. In: RIBEIRO, Paulo Rennes Marçal (Org.). Sexualidade e educação sexual: apontamentos para uma reflexão. Araraquara, SP: Cultura Acadêmica/Laboratório Editorial FCL, 2002, p. 916.

Educação sexual além da informação. São Paulo: EPU, 1990.

- Os momentos históricos da educação sexual no Brasil. In: RIBEIRO, Paulo Rennes Marçal (Org.). Sexualidade e educação: aproximações necessárias. São Paulo: Arte \& Ciência, 2004. p. 15-25.

SILVA, Tomaz Tadeu da. Documentos de identidade: uma introdução às teorias do currículo. 3. ed. Belo Horizonte: Autêntica, 2009.

SOARES, Wellington. Precisamos falar sobre Romeo. Nova Escola, São Paulo, n. 279, p. 24-31, fev. 2015.

STEINBERG, Shirley. R. Kindercultura: a construção da infância pelas grandes corporações. In: SILVA, Luiz Heron da; AZEVEDO, José Clóvis de; SANTOS, Edmilson Santos dos (Org.). Identidade social e a construção do conhecimento. Porto Alegre: SMED, 1997. p.98-145.

. KINCHELOE, Joel Layons. (Org.). Cultura infantil: a construção corporativa da infância. Rio de Janeiro: Civilização Brasileira, 2001.

STUMPF, Débora Karine. Representações de sexualidade no currículo da Nova Escola e a construção do sujeito heterossexual. 2003. 103 f. Dissertação (Mestrado).Universidade Federal do Rio Grande do Sul, Porto Alegre, 2003. 